\title{
Emocija besa - univerzalna ili kulturno specifična?**
}

\author{
Milica Tošić Radev* \\ Filozofski fakultet, Univerzitet u Nišu, Srbija \\ e-mail:psi736@gmail.com
}

\section{Aleksandar Baucal}

Filozofski fakultet, Departman za psihologiju, Univerzitet u Beogradu, Srbija

e-mail:abaucal@f.bg.ac.rs

\begin{abstract}
SAŽETAK Bazične emocije kao što su bes, tuga, strah i sreća su osnovne ljudske emocije, verovatno univerzalne i oblikovane evolucijom i biologijom. Međutim, za razliku od životinja, ljudi su kreativna bića, a najviši izraz ljudske kreativnosti je kultura. Svesno ili nesvesno ljudi prihvataju najveći deo svoje kulture koja na taj način oblikuje i naše emocije na društveno poželjan način. U radu smo izvršili detaljnu analizu kulturnih sličnosti i razlika u pojedinim komponentama emocionalnog procesa. To smo uradili na primeru jedne osnovne emocije, emocije besa, a poređenje je učinjeno duž pojedinih aspekata emocionalnog procesa koje predlaže kognitivni model emocija. Konkretno, posebno smo istakli sličnosti i razlike između kultura u događajima koji izazivaju emociju besa, načinu procene pojedinih događaja, fiziološkim reakcijama, spremnosti za akciju, načinu njenog izražavanja i regulacije.
\end{abstract}

Ključne riječi: emocija, bes, kulturne sličnosti i razlike.

* Stipendista Ministarstva prosvete i nauke Republike Srbije, angažovana na naučnoistraživačkom projektu broj 179002 koji finansijski podržava Ministarstvo prosvete i nauke u Srbiji

** Rad nastao u okviru rada na projektu br 179002 koji finansijski podržava Ministarstvo prosvete i nauke 


\section{Emocije-univerzalne ili kulturno specifične?}

Stepen u kome su emocije određene kulturom nije jasan i postoje brojne solucije u odnosu na problem biologija - sredina, koje se kreću od pretpostavke velikog stepena biološkog determinizma, koji ograničava mogućnost kulturnih varijacija, do pretpostavki o visokom stepenu savitljivosti emocija koji dozvoljava ili čak zahteva da se kulturni proces primeni na mnoge aspekte emocija. Za teoretičare evolucione perspektive emocije su univerzalni, široko rasprostranjeni afektivni programi nastali prirodnom selekcijom za podešavanje fizioloških, psiholoških i bihevioralnih parametara organizma na načine koji povećavaju sposobnost i sklonost da organizam u određenim situacijama odgovori adaptivno (prema Nesse, 1990.). Kritičari evolucione psihologije tvrde da se emocije razvijaju u određenoj sredini i one su društveno konstruisane. Najradikalniji, socijalni konstruktivizam, emocije vidi kao jednu od osnovnih veza između sebe i društva, one su društveni i kulturni artefakti, značenja koja su naučena kroz socijalnu interakciju u određenoj kulturi. Emocije su diskurzivni proces, društvene uloge koje ispunjavamo u svojim odnosima i mogu se shvatiti samo kao deo kulture u celini (Averill, 1980.). Međutim, čak i najviše biološki orijentisani teoretičari veruju da kultura određuje značajan broj događaja i pogodnosti različitih emocionalnih ponašanja i ekspresije, a i kulturalisti, ukazujući na biološku plastičnost koja omogućava modifikaciju emocija kod ljudi, na svoj način prihvataju važnu ulogu biologije (Parrott, 2001.).

Ipak, nalazi iz istraživanja ovih autora uglavnom se fokusiraju na različite teme, autori se koriste različitim metodama istraživanja i bave različitim aspektima emocija što rezultira prividno polarizovanom debatom i neuporedivošću dobijenih rezultata. Mi smatramo da se jedino integracijom nalaza iz različitih istraživačkih tradicija u široki okvir može delimično razjasniti pitanje o odnosu univerzalnosti ili kulturnoj specifičnosti emocija. S tim ciljem, mi ćemo nalaze porediti i tumačiti u okviru kognitivnog modela emocija koji predlažu Meskita i Frijda (Mesquita i Frijda, 1992.). U ovom modelu emocije se ne posmatraju kao jedinstveni entiteti, već kao proces u kome se mogu razlikovati sledeće sekvence: antecedentni događaj - procena događaja - fiziološke promene - spremnost za akciju - bihevioralna ekspresija - regulacija. Ovi autori takođe navode da je svaka emocija proizvod i prirode i okruženja, i da je za puno razumevanje emocija ljudi neophodno široko razumevanje obe teoretske perspektive. Emocije kod ljudi nisu impulsi u potpunosti biološki bazirani, niti kulturni artefakti isključivo konstruisani tokom bistvovanja individue u socijalnom Životu. Pitanje ne treba postaviti u smislu da li, ili ne, postoje kulturne varijacije, već pre u kom obimu, kom aspektu i na kom nivou analize se takve razlike pojavljuju (Mesquita i Frijda, 1992.).

Takođe, u cilju izbegavanja konfuzije naša analiza će ići po navedenim sekvencama, a biće fokusirana na jednu, izabranu bazičnu emociju, emociju besa. 


\subsection{Kros-kulturne sličnosti i razlike u antecedentima}

Ako se na emocije gleda kao da su evoluirale da se bave osnovnim zadacima života na načine koji su filogenetski adaptivni, onda je logično da će postojati neki zajednički elementi u kontekstima u kojima se emocije javljaju i univerzalnost u antecedentima bazičnih emocija među kulturama. S druge strane, verujemo da moraju postojati velike razlike pripisane socijalnom učenju i iskustvu. Pre svega, postoje dokazi da određene vrste događaja izazivaju određene, iste emocije u različitim kulturama. Pokazano je da se antecedenti emocija navedeni od strane pripadnika različitih zemalja Evrope, Izraela, Japana i Amerike mogu grupisati u šire kategrije kao što su: kontinuirani problemi u odnosima, gubici i slično, a koje važe za sve kulture. Na osnovu odsustva potrebe da se uvede kulturno-specifična kategorija antecedenata, zaključuje se o kros-kulturnoj sličnosti u vrsti situacija koje dovode do određenih emocija. Na primer, i za Amerikance i za Evropljane, najčešći antecedent besa jesu odnosi sa drugima (58\% i 39\%) i procenjena nepravda (21\%, 21\%). Slično, Japanci često, iako ne najčešće, kao povod za bes navode odnose (29\%) (Scherer et al., 1983.; 1988.; 1986., prema Mesquita i Frijda, 1992.). Slično ovome u dvema studijama (Boucher i Brandt, 1981.; Brandt i Boucher, 1985.) pripadnici različitih kultura, i to, Amerikanci i Malezijanci, u prvoj, a Amerikanaci, Koreanaci i Samoani, u drugoj, tačno su procenjivali koju emociju izaziva svaki od događaja u upitniku, koje su prethodno naveli članovi druge kulture kao antecedent određene emocije i nađeno je da su situacije koje vode do određenih osećanja u drugim kulturama identifikovane podjednako tačno kao izazivači datih emocija kao i situacije koje navode pripadnici sopstvene kulture.

Analizirajući navedene podatke Meskita i Frijda (Mesquita i Frijda, 1992.) navode da ove studije antecedente svrstavaju u vrlo široke i apstraktne kategorije, bez analize na konkretnom nivou u vidu specifičnih događaja kao što su "izdaja prijatelja", "bračni sukob" i sl., a da se upravo na ovom nivou mogu očekivati snažne kulturne specifičnosti. Dokaz za ovo postoji u studiji u kojoj je nađeno samo 8,5\% slaganja između ispitanika sa dva kraja Italije, pripadnika iste kulture, u njihovim navodima antecedenata pojednih emocija, ali potpuno slaganje kada su ti dogadaji kodirani na najapstraktnijem nivou (Galati i Sciaky, 1955., prema Parkinson, Fisher i Manstead, 2005.). Nepravda je tako uvek draž koja izaziva bes, u većini ili možda svim kulturama, ali šta će biti procenjeno kao nepravda se može razlikovati od kulture do kulture.

Kulturne razlike u situacijama koje izazivaju bes su pre svega pokazane opisima antropologa. Na primer, za Pintupi Aboridžine, pripadnike plemena iz australijske pustinje, bes znači negativnu procenu socijalnog stanja osobe i posledica je socijalnog odbacivanja. Ljudi su besni kada percipiraju odbijanje drugog, uskraćivanje simpatije i podrške, što sve znači nespremnost drugih da prepoznaju njihov odnos. Da bi se razumeo bes kod Pintupi plemena mora se znati značaj zajedničkog identiteta koji postoji u njihovoj kulturi. Njihov pojam besa je ugrađen u brigu da se osećaju potpunim kroz identitet sa drugima (Myers, 1988.). Za razliku od Pintupi, Luc (Lutz, 1982.) govori o konceptu "opravdanog besa" ili song kod pripadnika plemena 
Ifaluk. Da bi se kod njih javio bes neophodni su slučajevi koji ugrožavaju moralni poredak. Na kraju, postoje nalazi da Utku Eskimi (Briggs, 1970.) i Tabićani (Levy, 1973.; Solomon, 1984.) ne osećaju i ne ispoljavaju bes čak i pod takvim okolnostima koje bi se sigurno u Americi smatralo sramnim za prećutati.

Uglavnom se nađene kulturne razlike u antecedentima objašnjavaju time da se uslovi života razlikuju rezultirajući i razlikama u pojavi određenih događaja, a događaji usled različitih kulturnih verovanja mogu imati i različito značenje (Mesquita i Frijda, 1992.). Kao ekstreman primer, pominju se situacije koje se povezuju sa natprirodnim silama u nekim kulturama. Na primer, Surinamci veruju da nesreća može biti uzrokovana kletvama neprijatelja, te se njihovo ispoljavanje besa u susretu sa lošom srećom može razumeti samo ako se zna nešto o njihovom verovanju u crnu magiju (Wooding, 1981.; prema Scherer, 2001.a).

Čak i kada su emocije izazvane istom vrstom antecedenata u različitim kulturama, mogu i dalje postojati značajne razlike u frekvenciji. Na primer, Japanci navode "interakciju sa strancima” u vezi sa besom (52\%) znatno češće od evropskih (20\%) i američkih (15\%) ispitanika. S druge strane, za Amerikance, bes se javlja u kontekstu međuljudskih odnosa (58\%) pre nego što je to slučaj kod evropskih (39\%) i japanskih subjekata (29\%) (Scherer, Wallbott, Matsumoto i Kudoh, 1988.). I u drugim studijama je potvrđeno da Japanci izbegavaju bes u bliskim vezama, dok se doživljaj besa prvenstveno javlja u slučaju konfrontacije sa drugim grupama, dok Amerikanci i Evropljani izveštavaju o pojavi besa pre svega u prisustvu svojih bliskih i u odnosima sa njima (Matsumoto, Kudoh, Scherer i Wallbott, 1988.). Saglasan sa ovim je i nalaz Stipeka (Stipek et al, 1989.; prema Baumeister, 1999.) da u opisivanju situacija koje izazivaju bes, Kinezi češće navode one situacije kada se nešto desilo nekom drugom, na primer, dečak nije ustupio sedište starijoj ženi, dok je za Amerikance glavni stimulus za bes situacija u kojoj je žrtva sam pojedinac, na primer, prijatelj koji je prekršio obećanje.

Možemo zaključiti da su na najvišem nivou apstrakcije događaji koji izazivaju bazične emocije donekle univerzalni i opšti. Ali, na konkretnijem nivou analize, postoje značajne kulturne razlike u tome koji događaji pripadaju datoj opštijoj kategoriji, kako su kodirani i obojeni kulturnim shvatanjima i verovanjima, da li se i koliko često javljaju u datoj sredini i kakvo im se značenje pripisuje, što sve nije bez efekta na pojavu i prirodu emocionalne reakcije.

\subsection{Kros-kulturne sličnosti i razlike u obrascima procene}

Osnovna ideja teorije procene (Scherer, 2001.a) je da emocionalna reakcija ne zavisi od specifičnih karakteristika stimulusa i samog događaja, već pre od načina na koji mi procenjujemo ono što se dešava. Procena je, u stvari, kognitivna evaluacija događaja u smislu njegove očekivanosti i prijatnosti, stepena u kojem pomaže ili sprečava tekuće planove i ciljeve, stepena u kojem osoba veruje da je u stanju da se izbori sa događajem, stepena pravednosti, pripisane odgovornosti za događaj i sličnih dimen- 
zija procene. Ideja je da ukoliko ljudi iz različitih kultura procenjuju situaciju na isti način, oni će doživeti iste emocije, a ukoliko je procenjuju drugačije, to za posledicu ima i drugačije emocije (Scherer, 2001.a).

Studije u kojima se ispituje način procene događaja koji su antecedenti pojedinih emocija, kao što je na primer napad od strane drugog u slučaju besa, pokazuju vrlo sličan način njihove evaluacije duž velikog broja kultura (Mauro, Sato, Tucker, 1992.; Matsumoto et al, 1988.). Na primer, Holanđani, Surinamci i Turci procenjuju situaciju u kojoj postoji napad od strane nebliskih osoba kao neprijatnu, neočekivanu, štetnu po samopoštovanje a za koju je druga osoba odgovorna (Mesquita, 1993.). Slično, u studiji koja je obuhvatala 37 zemalja sa svih kontinenata, osim Antartika, utvrđeni su prilično stabilni kroskulturni obrasci procene. Bes je, svugde, izazvan situacijama koje su procenjene kao neočekivane, neprijatne, ometajuće po ciljeve osobe, nepoštene i izazvane akcijama drugih ljudi (Scherer, 1997.). I reči kojima se označava bes u različitim jezicima: japanskom, indonezijskom i holandskom, su procenjene slično, kao da se „sastoje od iskustva nečeg neprijatnog što ometa ostvarivanje ciljeva pojedinca, doživljava se kao nepravedno i neizbežno i za šta je neko drugi odgovoran ili kriv" (Frijda, Markam, Sato i Wiers, 1995.:139).

Sve ove studije sugerišu da iako na površinskom nivou analize situacije koje izazivaju emocije mogu biti različite, na ovom nivou, situacije koje izazivaju bes ipak su slične, i uvek doživljene kao neprijatne, nemoralne, nepoštene, nepravedne, a pripisivanje odgovornosti je uglavnom eksterno (Mesquita i Frijda, 1992.). Uprkos ovome, neke studije ukazuju i na značajne kulturne razlike u načinu procene, a one su posebno izražene upravo na dimenziji pripisivanja odgovornosti (Matsumoto et al., 1988.; Mauro et al., 1992.). Naime, nađeno je da Afrikanci antecedente svih negativnih emocija procenjuju kao značajno više nepoštene, uzrokovane spolja i nemoralne u odnosu na Latinoamerikance (Scherer, 1997.). Slično, Japanci češće od Holanđana ili Indonežana procenjuju situacije koje izazivaju bes kao nepromenljive i neizbežne (Frijda et al. 1995.). Takođe, Japanci su za razliku od američkih subjekata manje voljni da pripišu odgovornost, bilo sebi, bilo drugim ljudima, za bilo koje emotivno stanje (Matsumoto et al., 1988.).

Razlike u obrascima procene su u stvari razlike u sklonosti da se koriste pojedine dimenzije procene (Mesquita, Frijda, Scherer, 1997.). Konkretno, u nekoj kulturi može postojati sklonost da se odgovornost za neprijatne situacije pripiše drugim ljudima, što rezultira spremnošću za bes, a u drugoj kulturi, atribucija krivice može da bude manja ili potisnuta. Ove razlike u proceni mogu dovesti do razlika u vrsti događaja koji izazivaju određenu emociju, te bes može biti dobijen događajima koji izgledaju bezopasno, ili samo uznemirujuće, pripadnicima drugih grupa, što vodi i različitoj frekvenciji pojavljivanja tih emocija. Tako, Solomon (Solomon, 1978.) objašnjava nisku incidenciju besa među Utku kao posledicu nespremnosti da drugoj osobi pripišu krivicu za negativne događaje. Među Semai iz Malezije, takođe, tendencija da se pripiše krivica je slaba ili ne postoji, a Japanci pak češće pripisuju krivicu sebi, usled čega je od besa češće osećanje krivice (Lebra, 1983.; prema Mesquita i Frijda, 1992.). Tahićani imaju tendenciju da procenjuju po sebe negativne događaje kao podložne 
modifikaciji, kontroli i kao da stvarno ne utiču na njihove lične ciljeve, a postoji i naglasak na supstitutivne ciljeve i željene predmete, čime se objašnjavaju Tahićani u odnosu na odsustvo besa (Levy, 1973.). Nasuprot njima, Surinamci veruju da je nesreća uglavom uzrokovana ljudskim faktorom, te njihova tendencija da se razbesne može biti razumljiva činjenicom da je uvek pripisivanje krivice uključeno u njihovu procenu (prema Mesquita et al., 1997.).

Tako, postoje dokazi da su karakteristični načini procene situacija u vezi sa pojavom određenih emocija, pri čemu postoji interakcija između načina procene i kulture, što ukazuje na to da način procene može predvideti emocionalno iskustvo, ali donekle na različite načine u različitim kulturama.

\subsection{Kros-kulturne sličnosti i razlike u fiziologiji}

Veza između emocije i fiziologije tela je centralna pretpostavka pojedinih teorija emocija prema kojima je emocija percepcija određenih telesnih promena, a one nisu slučajne već pripremaju organizam za odgovarajuću akciju, što je pretpostavka identična sa evolucionim pristupom (npr. James, 1884.). Obimna literatura ukazuje na to da subkortikalni delovi mozga, u slučaju besa posebno amigdala, određuju i izazivaju pojavu emocije. Amigdala, naime, šalje impulse hipotalamusu, retikularnoj formaciji, facijalnim nervima, lokus coeruleusu i drugim strukturama koji dalje aktiviraju simpatički nervni sistem, pojačavaju reflekse, regulišu facijalnu ekspresiju, oslobađaju hormone: dopamin, norepinefrin i epinefrin što je sve karakteristično za emociju besa (Talarovicova, Krskova, Kiss, 2007.).

Kada je reč o specifičnijim fiziološkim funkcijama pojedninih organa, neki autori tvrde da postoje karakteristični obrasci aktivnosti autonomnog nervnog sistema za pojedine emocije. Ekman (Ekman, Levenson i Friesen, 1983.) smatra da se bes može diferencirati od ostalih emocija samo na osnovu dva parametra. Dok je rad srca usporen u slučaju sreće, gađenja i iznenađenja, puls raste u slučaju besa, straha i tuge. Takođe, dok se telesna temperatura ne menja u slučaju straha i tuge, u besu ona raste, te bi povišenje u pulsu i telesnoj temperaturi bilo karakteristično za bes. Slični podaci su dobijeni kasnije i kod nezapadnih, udaljenih kultura (Levenson., 1992.). Ovo je konzistentno i sa nalazima drugih autora koji navode da se čak i emocije besa i straha, koje inače imaju vrlo sličnu fiziološku podlogu, određenu visokim nivoom autonomičke aktivacije, ipak na nekoliko indikatora veoma razlikuju u stepenu (Ax, 1953.).

Na osnovu samoizveštaja ispitanika, a što predstavlja daleko lakši ali neprecizniji način ispitivanja fizioloških reakcija, utvrđene su još neke sličnosti, ali i varijacije među pripadnicima različitih kultura, u pogledu njihove percepcije fizioloških promena pri emocijama. Poređenje nalaza ovih studija je teško, ali nalazi ukazuju da postoji slaganje između grupa i da se gotovo u svim kulturama osećaj toplote, ubrzan rad srca, napetost mišića i promene u disanju najčešće javljaju pri opisu simptoma karakterističnih za ljutnju (Mesquita i Frijda, 1992.). 
Ipak, postoje i suprotni nalazi koji ne podržavaju rezultate o jedinstvenoj fiziologiji emocija. Neki autori ukazuju na to da se iste viscelarne promene događaju za krajnje različita emocionalna pa i neemocionalna stanja, i da sve emocije izazivaju generalni obrazac simptoma aktivacije simpatičkog nervnog sistema, ali ne postoje jasne razlike u fiziologiji koje bi jasno razlikovale različite emocije (Parrott, 2001.). Takođe, utvrđeno je da postoje i značajne razlike među kulturama u laičkim poimanjima telesnih promena koje prate emocije. Naime, nalazi ukazuju da Japanci prijavljuju značajno manje fizioloških simptoma u odnosu na Amerikance i Evropljane (Scherer et al, 1988.), a spontani opisi emocija Samoana i Ifaluka uopšte i ne sadrže pozivanje na telesne senzacije. Ovakvi stavovi su u skladu sa pristupom socijalnih konstruktivista koji smatraju da su fiziološki procesi za sve emocije isti, i da samo kognitivna procena i etiketiranje situacije razlikuju emocionalno iskustvo (Schachter i Singer, 1962.).

Na osnovu naše analize možemo videti da se i na nivou fiziologije mogu naći nalazi koji idu u prilog tome da je emocija besa univerzalna budući da je nezavisno od kulture regulisana funkcionisanjem istih, i to filogenetski najstarijih delova mozga. S druge strane, na fiziološkom nivou može biti nađen prostor i za kulturne varijacije u emocijama jer su ove subkortikalne strukture kod ljudi postale donekle kontrolisane moćnijim i važnijim kulturom posredovanim kortikalnim procesima.

\subsection{Kros-kulturne sličnosti i razlike u akcionim tendencijama}

Kada je reč o spremnosti za akciju, kao komponenti emocionalnog odgovora nema sistematskih istraživanja kulturnih razlika u dostupnim načinima delovanja i u spremnosti za akciju koje se javljaju u istim emocijama. Ipak, mi ćemo o akcionim tendencijama, kulturnim sličnostima i razlikama, diskutovati na osnovu samoizveštaja ispitanika i semantičke analize reči pojedinih emocija u različitim jezicima. Iako ne postoje čvrsti podaci, neki nalazi ipak sugerišu da su glavni oblici spremnosti za delovanje univerzalni i aktuelni u većini ili svim kulturama. U obimnoj studiji koja je obuhvatala ispitanike skoro svih kontinenata (Wallbott i Scherer, 1988.) ispitanici su pokazali sličnost u reakcijama koje prate iskustva pojedinih emocija. Između opštih tendencija: kretati se ka, kretati se od, kretati se protiv, bespomoćnosti i podnošenja, napad ili preduzimanje akcije protiv bila je često asocirana reakcija za bes.

Sa druge strane, propisi u različitim kulturama izgleda da propisuju drugačije vrste emocionalne reakcije, a to se vidi analizom reči kojima se označavaju reči, koje su uvek proizvod iskustva i života u određenoj kulturi. Na mnogim evropskim jezicima bes je asociran sa antagonizmom, otvorenim kriticizmom, hostilnošću, a ponekad i agresivnošću. Ovakvo naglašavanje otvorenog interpersonalnog ispoljavanja besa takođe karakteriše jezike Kaluli i Pakhtun gde je bes specifično asociran sa hladnokrvnom osvetom (Parkinson, 2005.). Štaviše, veoma različiti modeli odgovora se podrazumevaju i u konceptima drugih kultura i jezika. Pripadnici Ugande opisuju bes kao da sadrži više plača nego agresije (Davitz 1969.; prema Van Brakel, 1993.), a zamagljivanje između ljutnje i tuge može se videti i među Ilongot, plemena sa 
Filipina. Centralan u njihovoj kulturi je liget koji se obično prevodi kao bes, ali ne obuhvata samo ono što bes pokriva, već i čitav niz emocija, uključujući i tugu (Russell, 1991.). Dalje, Ifalukov song izgleda da uključuje manje hostilnosti i agresije od angloameričkog besa. On obuhvata i samoubilačke misli i postupke, oblike bola i tuge, a težnja da se nešto loše uradi nije usmerena ka drugoj osobi. Slično, reč za bes kod Utku, qiquq, podrazumeva nečujno povlačenje i ne progovaranje ni reči (Parkinson, 2005.).

Sve ovo ukazuje na postojanje sličnih akcionih tendencija u stanju besa, ali i na to da kultura posreduje emociju besa, u svim njenim aspektima, uključujući i vrstu i stepen akcione spremnosti.

\subsection{Kros-kulturne sličnosti i razlike u emocionalnoj ekspresiji}

Budući da je ekspresija emocija vid razmene informacija o opasnim događajima u sredini, dvosmislenost u ekspresiji imala bi visoku cenu te postoji univerzalnost u proizvodnji i percepciji emocija. Kod ljudi, ipak, postoji i varijabilnost u afektivnoj komunikaciji određena kulturnim pravilima koja određuju vrste konteksta u kojima se javljaju emocije, kao i vrste obrazaca ponašanja povezane sa njima.

U velikom broju objavljenih studija kojima su obuhvaćene mnoge moderne ali i izolovane kulture potvrđeno je da postoji univerzalna facijalna konfiguracija za oko sedam emocija. U besu ona ima sledeća svojstva: spušteno i naborano čelo, spojene obrve sa izdignutim spoljašnjim krajem, otvorenim očima, zategnutim kapcima, namrštenim nosem, stisnutim usnama sa pokazanim zubima i izbačenu bradu, a neke od ovih akcija su delovi reakcije napada koja se vida i kod ljudskih predaka (Ekman, 1978.). Ekman je u nizu radova pokazao da ljudi iz različitih kultura tačno identifikuju određene emocije na osnovu fotografija facijalne ekspresije, uključujući i pripadnike izolovanih, nepismenih kultura, kao što je pleme Fore sa Nove Gvineje, čime se isključuje mogućnost da je visoka stopa saglasnosti posledica učenja signala drugih kultura putem modernih sredstava komunikacije (Ekman i Friesen, 1971.). Takođe, članovi svih kultura pokazuju iste izraze lica kada poziraju i izražavaju pojedine emocije (Ekman, 1972.). Pored ovih, već klasičnih studija, i studije koje ispituju korelaciju pokreta lica sa samoizveštajem o emociji, studije posmatranja facijalne ekspresije kod odojčadi i dece rođene slepe daju podršku univerzalističkoj tezi (Russell, 1994.). Sve one podržavaju Darvinov predlog da je facijalna ekspresija emocija slična među ljudima, bez obzira na kulturu, jer je evolutivnog porekla i Tomkinsovu teoriju koja postulira urođen subkortikalni program koji povezuje određene draži sa univerzalnim izrazom lica za svaku od primarnih emocija.

Neke studije, međutim nalaze gotovo jednak iznos varijanse koji je u facijalnoj ekspresiji objašnjen vrstom emocije i zemljom porekla i zaključuju da postoje kroskulturne razlike u facijalnoj ekspresiji (Wallbott i Scherer, 1988.). One su očigledne posebno u stopi prepoznavanja i proceni intenziteta facijalne ekspresije. Na primer, 
dok 89,2\% Amerikanaca tačno procenjuje bes na slici, to uspeva samo 56.8\% Japanaca i 50,8\% Afrikanaca (Izard, 1971.; prema Russell, 1994.). Slično su nađene niže stope prepoznavanja emocija kod Etiopljana u odnosu na Kanađane i Zambijaca u odnosu na normativni američki uzorak (prema Russell, 1994.). I sam Ekman navodi da u odnosu sa američkom stopom prepoznavanja, tačnost prepoznavanja pripadnika plemena Fore, iako premašuje slučajnost, je smanjena za 20-25\% (Ekman, 1982.; prema Mesquita i Frijda, 1992.). Sorenson (Sorenson, 1976.; prema Russell, 1991.) ističe da je za pripadnike plemena Fore reč za bes modalni odgovor za izraze besa, prezira i tuge, a slično su i pripadnici Babinemo plemena sa Nove Gvineje imali tendenciju da sve izraze lica Amerikanaca na Ekmanovim fotografijama vide kao "besne" (Sorenson, 1975.; prema Elfenbein i Ambady, 2002.). Rezimirajući brojne studije Rasel (Russell, 1994.) navodi da stepen slaganja u proceni opada sve više što su kulture međusobno dalje i što su imale manje međusobnih kontakata. Dok pripadnici zapadnih kultura bes identifikuju tačno u 81,2\% slučajeva, razvijene nezapadne kulture u 63\%, a nepismene, izolovane u 56\% slučajeva. Kulturne razlike u oceni intenziteta izraza lica su dobro dokumentovane i jedan od najpouzdanijih nalaza je da Amerikanci procenjuju emotivne izraze lica intenzivnije nego Japanci (Matsumoto i Ekman, 1989.).

Rasel (Russell, 1994.) kritikuje korišćene metode, navodeći da prinudni-izbor odgovora, dizajn sa ponovljenim ispitanicima (within-subject dizajn) i već odabrane fotografije nespontanih izraza lica mogu uticati na nalaze o univerzalnosti i smatra da se promenom metoda manje podržavajući ili čak suprotni zaključci mogu izvući. Naime, subjekti daju mnogo veći broj odgovora kada im je dozvoljeno da za svaku fotografiju daju svoju oznaku. Ekspresiju za bes, u slučaju slobodnog izbora, ispitanici tako pre ocenjuju kao frustraciju (40\%), odlučnost $(31,7 \%)$, tek zatim kao bes (12.5\%), a i neprijateljstvo (9,2\%), mržnju (2.5\%), ljubomoru (2.5\%) i bol (1,7\%). (Russell, 1993.). Za razliku od 60,7\% tačnog prepoznavanja besa kada su subjekti upoznati sa svim fotografijama, bes je tačno identifikovan u 40,2\% kada im je pokazana samo fotografija besa za zadatkom da procene emociju na slici (Matsumoto i Ekman 1998.; prema Russell, 1994.). Na kraju, ima podataka koji ukazuju da je prepoznavanje poziranih izraza lica znatno bolje $(81,4 \%)$ nego spontanih izraza $(26,0 \%)$ kod kojih se stopa procene i ne razlikuje od procene koja bi bila dobijena slučajnim izborom, osim za srećan izraz (Motley i Camden, 1988.; prema Russell, 1994.). Studije koje koriste multidimenzionalnu procenu pokazuju da posmatrači vide više emocija kada prosuđuju dat emocionalni izraz što može dovesti u pitanje postojanje univerzalnih kategorija emocija. Procenjujući kvantitativno, na skali od 1-8, a na više dimenzija, ispitanici facijalnu ekspresiju besa ocenjuju ocenom 6 za bes, ali i ocenama 5, 6 za gađenje; 5, 3 za tugu; 4, 9 za strah i tako dalje (Russell i Bullock, 1986.; prema Russell, 1994.). Štaviše, kulture se jasno razlikuju i u ovakvom ispitivanju. Ne samo da Amerikanci sa većom tačnošću procenjuju bes i vide ga kao intenzivniji, već takođe vide u ekspresiji karakterističnoj za bes više prezira i gađenja nego Japanci. Japanski procenjivači pak vide više tuge nego Amerikanci. (Yrizarry, 1998.). Na osnovu svega Rasel (Russell, 1994.) smatra da samo jedan metod, diskutabilne valjanosti, podržava pretpostavku o pan-kulturalnom prepoznavanju univerzalnih facijalnih ekspresija bazičnih emocija. 
Facijalna ekspresija je najbolje ispitan vid izražavanja emocija. Pored nje, postoje dokazi da i telesnu gestikulaciju i prozodijske odlike govora karakterišu stereotipne konfiguracije koje su na sistematičan način povezane sa emocijama. Na primer, bes uključuje ugaoni položaj tela, prenos težine napred, ramena rigidno postavljena sa strane, grudi raširene i izbačene napred i spuštenu glavu (prema Tan i Nareyek, 2009.), a vokalizacija besa ima tendenciju da bude brz govor po tempu, glasna po intenzitetu, visokog tona, energična, visoka po varijabilnosti u visini, uglavnom sa porastom visine u melodiji i sa mikrostrukturalnim nepravilnostima (Patel, 2008.). Ovi nalazi su slični onima o facijalnoj ekspresiji, nalazeći kod subjekata različitih po poreklu, dobro međusobno prepoznavanje emocija koje su prezentovane samo telesno ili vokalno (Scherer, Schorr i Johnstone, 2001.b) pa izgleda da svi ovi kanali komunikacije omogućavaju ljudima da dele osnovne emocije preko jezičkih i kulturnih granica.

U suštini, ovi nalazi, uz izvesna ograničenja i kritike, pokazuju da postoje pankulturni elementi u neverbalnim izrazima emocija, ali samo u slučaju kada njihovo ispoljavanje nije regulisano ili pojava uopšte, određena dejstvom kulture.

\subsection{Kros-kulturne sličnosti i razlike u regulaciji}

Meskita (Mesquita, 2001.b; prema Oatley, Keltner i Tucjer, 2006.) razlikuje praksu emocija od emotivnog potencijala. Svi ljudi imaju potencijala i stavljeni u eksperimentalne situacije ce zaista imati univerzalne emocionalne odgovore u terminima iskustva, ekspresije i fiziologije. Ali, konkretna emocionalna realnost, među kulturama, može široko varirati. Ljudi usvajaju veći deo svoje kulture, a kada je reč o emocijama, pre svega se misli na to da su emocije predmet regulisanja, i to na svim nivoima, u smislu: kodiranja događaja u određenu vrstu, procenu tipa na određen način, a ponašanja mogu biti potisnuta, maskirana ili naprotiv, izraženija. U svakoj kulturi postoje određena, često različita pravila o tome kako, kada, i kome ljudi treba da izraze svoja emocionalna iskustva.

Kada je reč o regulaciji kao aspektu emocionalnog odgovora i razlikama između kultura, najbolje su ispitane razlike između individualističkih i kolektivističkih kultura. U individualističkim kulturama emocije se smatraju važnim ličnim iskustvima, predstavljaju prava pojedinca i smeju se slobodno i spontano izražavati. U kolektivističkim kulturama koje više nego pojedinca vrednuju grupu i harmoniju u grupi, emocije su viđene kao iskustva interakcije, one odražavaju društveni kontekst pre nego unutrašnje stanje pojedinca, a izražavanje emocija je pod kontrolom, jer njihova ekspresija mora da uzme u obzir procenu veze između sebe i drugih (Mesquita, 2000.). Živeći u određenoj kulturi, ljudi usvajaju ova načela, a ovo se svakako mora odraziti na to šta će kod pripadnika ovih kultura izazivati bes i da li će se on otvoreno izraziti. Nalazi potvrđuju da se u zapadnim kulturama bes smatra načinom odbrane i opravdan je sve dok je proporcionalan ozbiljnosti pretnje i izražen na socijalno odgovarajući način. Izražavanje besa je potrebno jer je u interesu zaštite individualnih prava i sloboda. Na primer, Nemci pokazivanje besa ne vide kao sra- 
mno i smatraju da može biti neophodno u nekim situacijama da bi se ostvario cilj. On je oblik davanja povratne informacije drugom, koji nas je razbesneo i služi kao efikasna strategija za promenu ponašanja druge osobe (Bender, 2007.). Takođe, ispoljiti bes prema ljudima koje znamo i volimo kod Ameriknaca je sasvim prihvatljivo (Markus i Kitayama, 1991.; prema Oatley et al., 2006.) i oni ga ispoljavaju najmanje jednom nedeljno, najčešće prema najbližima, a razlozi koji se navode su potvrditi nezavisnost ili poboljšati sliku o sebi (Averil, 1982.; prema Oatley et al., 2006.).

U kolektivističkim kulturama pokazivanje besa nije prihvatljivo jer ugrožava autoritet i harmoniju u odnosima (Miyake i Yamazaki, 1995.; prema Safdar, Matsumoto, Kwantes, Friedlmeier, Hee Yoo i Kakai, 2009.). Na činjenicu da Japance karakteriše veća kontrola emocija nego Amerikance ukazao je još Ekman (Ekman i Friesen, 1972.; prema Matsumoto i Ekman, 1989.) u veoma citiranoj studiji u kojoj je našao da ove dve grupe imaju isti izraz lica kada gledaju emocionalni film sami, ali Japanci pokazuju više pozitivnih i manje negativnih izraza kada je eksperimentator prisutan. I druge studije pokazuju da je kod Japanaca doživljaj besa redak, a smatra se posebno neprikladnim ispoljiti bes prema članovima svoje grupe, porodici, rođacima i kolegama (Markus i Kitayama, 1991.; prema Oatley et al., 2006.). Slično, centralni moral među Utku Eskimima je kontrola emocija. Bes se vidi kao loša emocija koja nikada nije opravdana. Budući da ljute misli vode do ljutih dela, bes ne bi trebalo izražavati, a ljudi treba da budu prepuni smeha i dobre volje (Briggs, 1970.). Oni nemaju ni reč za bes u svom vokabularu, a koriste reč koja se prevodi kao „detinjasto“ da označe agresivna ponašanja kada su ona opažena kod stranaca (Calhoun i Solomon, 1984.; prema Russell, 1991.). I na Tahitiju, bes se smatra vrlo opasnim i ne postoji njegovo izražavanje (Levy, 1973.; Solomon, 1984.). Smatra se da ni oni ne potiskuju svoj bes, već shvataju važnost prisustva drugih i ljubaznosti u svim situacijama, što za posledicu ima vrlo malo doživljaja besa. U ovim kulturama realna agresija je ograničena na retke okolnosti, a hostilnost se eventualno ispoljava u malim delima, kao što su tračarenje, hladnoća ili povlačenje (prema Mesquita i Frijda, 1992.). I za pleme Tongan, bes je emocija koja remeti društvene odnose i ocenjuje se kao negativna i socijalno neodobrena (Bender, 2007.). Ilongot ljudi sa Filipina imaju veliki strah od toga da emotivni potencijal može da dovede do prekida društvenih odnosa, te odmah otklanjaju jake emocije kako bi se obezbedili prijateljski odnosi. Ovaj proces sprečava da frustracija postane bes (Rosaldo, 1984.; prema Ratner, 2000.). Za razliku od ovih kultura u kojima se bes kontroliše, postoje plemena domorodaca i ratnika u kojima se bes smatra normalnim, kao što je Kaluli. Tu se smatra da je ljuta osoba pretrpela neki gubitak i ima pravo na naknadu, pa se izražavanje besa očekuje. Slično, pripadnici plemena Janomamo sebe smatraju besnim ljudima, bes se kultiviše, deca se od najranijih dana uče da budu agresivna i česti su različiti oblici nasilja i obračuna (Mesquita i Frijda, 1992.).

Tako, emocije nisu valuta koja omogućava direktnu razmenu. One mogu biti regulisane i shvaćene drugačije od jedne do druge kulture, pa reći da si besan može podrazumevati da si nezreo i detinjast ili pošten i častan te se emocije mogu posmatrati kao kulturna praksa koje promoviše važne kulturne ideje. 


\section{Diskusija}

Kultura se može definisati kao "skup stavova, ponašanja i simbola koje deli velika grupa ljudi i obično se prenosi sa jedne generacije na sledeću" (Shiraev i Levy, 2004.:4), a sastoji se od "obrazaca načina razmišljanja, osećanja, i reagovanja" (Kluckhohn, 1951.) U našem radu pokazali smo da emocija besa, koja sigurno ima svoje biološke korene, makar delom jeste proizvod i kulturne izgradnje kroz socijalizaciju pojedinca i njegovo iskustvo u određenom društveno-kulturnom kontekstu.

Nalazi istraživanja kros-kulturne psihologije potvrđuju našu polaznu pretpostavku da postoje razlike u načinu i stepenu regulacije pojedinih emocija, a u skladu sa njom, ili nezavisno, zabeležene su i razlike u vrsti specifičnih događaja koji izazivaju određenu emociju u određenoj kulturi, stopi pojave tih događaja, njihovom kodiranju i kulturnom značenju, načinu njegove procene duž dimenzija koje su važne za pojavu date emocije, spremnosti za akciju, a manje i u karakteristikama i intenzitetu bihevioralnog i fiziološkog odgovora organizma. Sa druge strane, bes se javlja u svim kulturama, rečnici većine jezika imaju oznaku za ovu emociju, koja je često i izazvana sličnim kategorijama stimulusa kao što je npr. nepravda, a koja je uvek doživljena kao nepravedna i često izražena telesno ili ponašajno na isti način, posebno onda kada se javlja nevoljno, impulsivno i automatski.

U stvari, naša analiza pokazuje da su oba pristupa o poreklu emocija, drugačijih shvatanja, evolucioni i kulturološki, u pravu i štaviše, tek uzeti kao komplementi, a ne suprotni, mogu najkompletnije objasniti emocije. Naime, bes je zaista emocija koja se javlja rano u razvoju, univerzalna je, a javlja se i kod ljudskih predaka. Regulisana je filogenetski starim strukturama mozga i njena ekspresija je automatska i univerzalna. Međutim, ovo je tačno samo ukoliko se posmatra sirovi, neposredovan bes, a koji se, iako retko, ipak nalazi u repertoaru ponašanja ljudi, u situacijama kada se on javlja automatski, nezavisno od naše volje, kontrole i svesti. Međutim, u većini situacija, kultura određuje način procene situacije, definisanje onoga šta osoba oseća, doživljaj same emocije i akcione tendencije i način izražavanja i često je on potpuno svesna, voljna, a nekad i instrumentalna emocija. Na kraju, želimo da naglasimo i drugi stav u okviru sociokulturne psihologije, koji sledi liniju razmišljanja koju je definisao Vigotski. Po našem mišljenju, primena teorije Vigotskog na emociju besa je značajna jer donekle pravi kompromis između evolucionističkih i kulturalističkih teorija, priznajući da je čovek ujedno i biološko i socio-kulturno biće. Naime, prema teoriji, mi se rađamo sa nižim mentalnim funkcijama, biološki nasleđenim, univerzalnim obrascima ponašanja i onime po čemu smo slični ostalim Životinjama. Specifično ljudsko ponašanje, međutim, nije direktna reakcija na objekte, već je oblikovano oruđima i znakovima koji su socijalne i kulturološke tvorevine. Sve ljudske mentalne funkcije, uključujući i emocije su socio-kulturne prirode, a razvojne novine nastaju i transformišu se kroz socijalnu interakciju koja je uklopljena u određeni socijalni i kulturološki okvir. I bes, kao bazična emocija, tako može biti u određenim situacijama kod ljudi sličan životinjskom i imati sva svojstva niže mentalne funkcije: nevoljnost, univerzalnost, automatizam, ali je češće, kod ljudi, on viša mentalna funkcija, posredovana kulturom, nastala medijacijom niže mentalne funkcije od strane simbola i drugih socijalnih i kulturnih „oruđa“. Štaviše, svi nalazi 
idu u prilog navedenom shvatanju. Kada ne postoje zahtevi da se bes maskira, ekspresija je univerzalna, ali je u realnom životu ona uvek posredovana pravilima date kulture. Bes se zapravo kod ljudi može pojaviti kao primarna, bazična, biološka, u stvari niža mentalna funkcija, zasnovana na biološkoj programiranosti i evolutivnom softveru, nevoljan, automatski način reagovanja na određeni tip stimulacije, ali i kao viša mentalna funkcija koja je posredovana kulturnim značenjima i drugim medijatorima, i koja ima određenu kontrolu i svesnost.

\section{Zaključak}

Na pitanje o poreklu i prirodi emocija možemo sa sigurnošću odgovoriti da emocije uopšte, zavise od biologije. Postoji ogroman broj dokaza da su emocije povezane sa starim strukturama mozga, praćene su promenama u našem autonomnom nervnom sistemu i ove promene je veoma teško kontrolisati. Emocije su slične omome što se javlja i kod životinja, a u razvoju pojedinca pojavljuju se rano, pre nego što je bilo vremena za učenje kulture. Ipak, varijabilnost u frekvenciji pojave pojedinih emocija i intenzitetu njihovog izražavanja i razlike u vokabularu emocija pružaju dokaze koji idu u prilog socijalno-kulturalističkoj tezi koja navodi da su kod ljudi koji su kultivisana i kognicijom obdarena bića, emocije donekle oblikovane i usklađene kulturnim propisima i očekivanjima. Suština je da emocionalni sindrom uključuje više različitih elemenata, neki od njih su biološkog, drugi socijalnog porekla, ali ni jedan od njih zasebno nije dovoljan za identifikaciju sindroma u celini (Averill, 1980.). Analiza je pokazala da razlike u nekim aspektima emocija ne moraju nužno implicirati razlike u drugim aspektima emocionalnog odgovora, a kulturne sličnosti u jednom pogledu ne garantuju sličnosti u svakom drugom. Glavni zaključak našeg razmatranja je da globalne izjave o kros-kulturnoj univerzalnosti emocija, ili o njihovoj kulturnoj relativnosti i određenosti nisu prikladne. Umesto toga, procena bi trebalo da počne sa analitičkim pristupom emotivnom procesu, razlikujući determinante za različite komponente. Ukoliko sumiramo sve rečeno, i donekle generalizujemo, izleda da ipak postoji univerzalnost u pogledu facijalne ekspresije, intonacije glasa kao i fizioloških odgovora. Možda postoje i vrste događaja, češće povezane sa određenim emocijama, a postoje dokazi za sličnost u dimenzijama procene. Što se tiče kulturnih razlika, njihov glavni izvor se odnosi na proces regulacije, a posredstvom njega se dalje mogu javiti razlike i u ostalim komponentama u vidu traženja ili izbegavanja određene vrste događaja koji izazivaju određene emocije, supresiji određenih načina procene, učestalosti, karakteristike i intenziteta ekspresivnog ponašanja.

Uz priznanje da su bazične emocije u velikoj meri zajedničke ljudima i da predstavljaju važan pankulturni kanal komunikacije, one su u različitim kulturama, na različite načine i u različitoj meri, nijansirane njenim uticajem. 


\section{Literatura}

1. Ax, A. A. (1953). The psychological differentiation between fear and angerin humans. Psychosomatic Medicine, 15 (5): 433-442.

2. Averill, J. R. (1980). A Constructivist View of Emotions, in: Robert Plutchik and Henry Kellerman (Eds.). Theories of Emotion. New York: Academic Press.

3. Baumeister, R. F. (1999). The self in social psychology. Philadelphia, PA: Psychology Press.

4. Bender, A.; Spada, H.; Seitz, S.; Swoboda, S.; Traber, S. (2007). Anger and rank in Tonga and Germany: Cognition, emotion, and context. Ethos, 35 (2): 196-235.

5. Boucher, J. D. and Brandt, M. E. (1981). Judgement of emotion: American and Malay antecedents. Journal of Cross-Cultural Psychology, 12 (3): 272-283.

6. Brandt, M. E. and Boucher, J. D. (1985). Judgments of emotions from the antecedent situations in three cultures, in: I. R. Lagunes and Y H. Poortinga (Eds.). From a different perspective: Studies of behavior across cultures. Lisse, The Netherlands: Swets \& Zeitlinger.

7. Briggs, J. L. (1970). Never in Anger: Portrait of an Eskimo Family. Cambridge: Harvard University Press.

8. Ekman, P. (1999). Basic emotions, in: T. Dalgleish and M. Power (Eds.). Handbook of Cognition and Emotion. Sussex, U.K.: John Wiley \& Sons, Ltd.

9. Ekman, P.; Friesen, W.V. and Hager, J. (1978). Facial Action Coding System The Manual. Salt Lake City, UT: Research Nexus Division of Network Information Research Corporation.

10. Ekman, P.; Levenson, R. W. and Friesen, W. V. (1983). Autonomic Nervous System Activity Distinguishes among Emotions. Science, New Series, 221 (4616): 1208-1210.

11. Ekman, P. (1972). Universals and cultural differences in facial expressions of emotion, in: J. Cole (Ed.). Nebraska Symposium on Motivation. Lincoln: University of Nebraska Press.

12. Ekman, P. and Friesen, W. V. (1971). Constants across culture in the face and emotion. Journal of Personality and Social Psychology, 17 (2): 124-129.

13. Elfenbein, H. A. and Ambady, N. (2003). Universals and cultural differences in recognizing emotions. Current Directions in Psychological Science, 12 (5): 159164.

14. Frijda, N.; Markam, S.; Sato, K.; Wiers, R. (1995). Emotions and emotion words, in: Russel, J. A.; Fernández-Dols, J. M.; Manstead, A.S.R.; Wellenkamp, J.C. (Eds.). Everyday conceptions of emotion. Dordrecht: Kluwer.

15. Hess, U. (2001). The experience of emotion: Situational influences on the elicitation and experience of emotions, in: A. Kaszniak (Ed.). Emotions, Qualia, and Consciousness. Singapore: World Scientific Publishing.

16. James, W. (1884). What is an emotion?. Mind, 9: 188-205.

17. Kluckohn, C. (1951). Values and value orientation in the theory of action, in: T. Parsons and E. Shils (Eds.). Toward a general theory of action. Cambridge, MA: Harvard University Press.

18. Levenson, R. W. (1992). Autonomic Nervous System Differences among Emotions. Psychological Science, 3 (1): 23-27. 
19. Levy, R. I. (1973). Tahitians: Mind and experience in the Society Islands. Chicago: University of Chicago Press.

20. Lutz, C. (1982). The domain of emotion words on Ifaluk. American Ethnologist, 9 (1): 113-128.

21. Matsumoto, D. and Ekman, P. (1989). A American-Japanese Cultural Differences in Intensity Ratings of Facial Expressions of Emotionmerican. Motivation and Emotion, 13 (2): 143-157.

22. Matsumoto, D.; Kudoh, T.; Scherer, K. R.; Wallbott, H. (1988). Antecedents of and reactions to emotions in the United States and Japan. Journal of CrossCultural Psychology, 19 (3): 267-286.

23. Mauro, R.; Sato, K. and Tucker, J. (1992). The role of appraisal in human emotions: A cross-cultural study. Journal of Personality and Social Psychology, 62 (2): 301-317.

24. Mesquita, B. (1993). Cultural variations in emotions. A comparative study of Dutch, Surainamese, and Turkish people in the Netherlands. Unpublished PhD thesis. Amsterdam: University of Amsterdam.

25. Mesquita, B. (2000). Emotions in collectivist and individualist contexts. Journal of Personality and Social Psychology, 80 (1): 68-74.

26. Mesquita, B.; Frijda, N. H. and Scherer, K. R. (1997). Culture and emotion, in: J. W. Berry (Ed.). Handbook of cross-cultural psychology, Vol. 2, Basic processes and human development. Boston, MA: Allyn \& Bacon.

27. Mesquita, B. and Frijda, N.H. (1992). Cultural Variations in Emotions: A Review. Psychological Bulletin, 112 (2): 179-204.

28. Myers, F.R. (1988). The logic and meaning of anger among Pintupi Aborigines, Man. New Series, 23 (4): 589-610.

29. Nesse, R. M. (1990). Evolutionary explanations of emotions. Human Nature, 1 (3): 261-289.

30. Oatley, K.; Keltner, D. and Jenkins, J.M. (2006). Understanding emotions (2nd ed). Malden, MA: Blackwell Publishing.

31. Ortony, A. and Turner, T. J. (1990). What's Basic About Basic Emotions?. Psychological Review, 97 (3): 315-331.

32. Parkinson, B.; Fischer, A. A. and Manstead, S.R. (2005). Emotion in social relations: cultural, group, and interpersonal processes. New York, NY: Psychology Press.

33. Parrott, W.G. (2001). Emotions in social psychology: Essential readings. Philadelphia, PA: Psychological Press.

34. Patel,A.D. (2008). Music, language, and the brain. Oxford: Oxford University Press.

35. Prinz , J. J. (2004). Which Emotions Are Basic?, in: D. Evans and Pierre Cruse (Eds.). Emotion, Evolution, and Rationality. Oxford: Oxford University Press.

36. Ratner, C. (2000). A cultural-psychologicalanalisis of emotion. Culture and Psychology, 6 (1): 5-39.

37. Russell, J., A. (1994). Is There Universal Recognition of Emotion From Facial Expression? A Review of the Cross-Cultural Studies. Psychological Bulletin, 115 (1): 102-141.

38. Russell, J. A. (1993). Forced-choice response format in the study of facial expression. Motivation and Emotion, 17 (1): 41 -51. 
39. Russell, J. A. (1991). Culture and the Categorization of Emotions. Psychological Bulletin, 110 (3), 426-450.

40. Safdar, S.; Matsumoto, D.; Kwantes, C.T.; Friedlmeier, W.; Hee Yoo, S.; Kakai, H. (2009). Variations of Emotional Display Rules Within and Across Cultures: A Comparison Between Canada, USA, and Japan, Canadian. Journal of Behavioural Science, 41 (1): 1-10.

41. Schachter, S. and Singer, J. E. (1962). Cognitive, Social, and Physiological Determinants of Emotional State. Psychological Review, 69 (5): 379-399.

42. Scherer, K. R.; Schorr, A. and Johnstone, T. (2001a). Appraisal processes in emotion: theory, methods, research. New York, NY: Oxford University Press.

43. Scherer, K. R.; Banse, R. and Wallbott, H. (2001b). Emotion inferences from vocal expression correlate across languages and cultures. Journal of Cross-Cultural Psychology, 32 (1): 76-92.

44. Scherer, K. R. (1997). The role of culture in emotion-antecedent appraisal. Journal of Personality and Social Psychology, 73 (5): 902-922.

45. Scherer, K. R.; Wallbott, H. G.; Matsumoto, D.; Kudoh, T. (1988). Emotional experience in cultural context: A comparison between Europe, Japan, and the United States, in: K. R. Scherer (Ed.). Facets of emotions. Hillsdale, NJ: Erlbaum.

46. Shiraev, E. and Levy, D. (2004). Cross-cultural psychology. Boston: Pearson Education, Inc.

47. Solomon, R. C. (1984). Getting angry: the Jamesian theory of emotion in anthropology, in: Richard A. Shweder and Robert A. LeVine (Eds.). Culture theory: essays on mind, self and emotion. Cambridge, England: Cambridge University Press

48. Solomon, R. S. (1978). Emotions and anthropology: The logic of emotional world views. Inquiry, 21: 181-199.

49. Tan, S. C. G. and Nareyek, A. (2009). Integrating Facial, Gesture, and Posture Emotion Expression for a 3D Virtual Agent, in: Proceedings of the 14th International Conference on Computer Games: AI, Animation, Mobile, Interactive Multimedia, Educational \& Serious Games. (CGames 2009 USA), 23-31.

50. Talarovicova, A.; Krskova, L. and Kiss, A. (2007). Some assessments of the amygdala role in suprahypothalamic neuroendocrine regulation: a minireview. Endocrine Regulation, 41 (4):155-162.

51. Yrizarry, N.; Matsumoto, D. and Wilson-Cohn, C. (1998). American-Japanese Differences in Multiscalar Intensity Ratings of Universal Facial Expressions of Emotion. Motivation and Emotion, 22 (4): 315-327.

52. Van Brakel, J. (1993). Emotions: A Cross-Cultural perspective on forms of life, in: Social Perspectives on Emotion, Vol. II. Greenwich, CN: Jai Press.

53. Wallbott, H. G. and Scherer, K. R. (1988). How universal and specific is emotional experience? Evidence from 27 countries, in: K. R. Scherer (Ed.). Facets of emotions. Hillsdale NJ: Erlbaum. 
Milica Tošić Radev

Faculty of Philosophy, University of Niš, Serbia

e-mail:psi736@gmail.com

Aleksandar Baucal

Faculty of Philosophy, Department of Psychology, University of Belgrade, Serbia

e-mail: abaucal@f.bg.ac.rs.

\title{
Anger - Universal or Culture Specific?
}

\begin{abstract}
Basic emotions, such as anger, grief, fear and happiness, are essential human emotions, possibly universal and shaped by evolution and biology. However, unlike animals, humans are creative creatures, and the highest expression of that creativity is culture. Consciously or unconsciously we adopt the biggest part of our culture and thus shape our emotions in a socially desirable way. We have performed a detailed analysis of cultural similarities and differences in certain components of the emotional process. We have analysed one basic emotion, anger, and compared various aspects of the emotional process as proposed by the cognitive model of emotions. Specifically, we have pointed out similarities and differences in cultures regarding the events which provoke anger, the assessment of particular events, physiological reactions, readiness to act, the expression and control of action.
\end{abstract}

Key words: emotion, anger, cultural similarities and differences. 